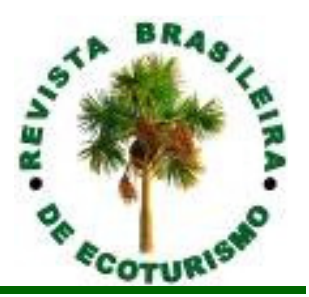

\title{
A Gestão e a Sustentabilidade na Atividade Turística: uma análise das discussões na última década no Brasil
}

\author{
Management and Sustainability in Tourism Activity: an analysis \\ of the discussions in the last decade in Brazil
}

\author{
Nathália Roncada de Freitas, Paulo Augusto Ramalho de Souza, \\ Elisandra Marisa Zambra, Maria do Carmo Romeiro, Raquel da Silva Pereira
}

\section{RESUMO}

Em razão da importância do turismo como atividade econômica para o Brasil e o seu efeito no meio ao qual ele está inserido, para tal, questiona-se entender as discussões referentes ao tema nos últimos dez anos. Esse estudo tem como objetivo geral analisar as principais discussões referentes ao tema sustentabilidade na atividade turística do Brasil na última década. Como objetivos específicos pretende-se: identificar as principais abordagens dentro do tema sustentabilidade na atividade turística do Brasil e discutir de que modo as variáveis contribuem e/ou afetam a sustentabilidade na atividade turística. Por fim, conclui-se que as variáveis são interdependentes, uma complementa a outra, e a pesquisa de todas como um conjunto colabora para o crescimento e melhor qualidade da sustentabilidade na atividade turística. Porém, a falta de pesquisas na área ainda é grande, mesmo estando em evidência o tema sustentabilidade, quando comparado a quantidade de artigos publicados em periódicos, verifica-se que é pouco debatido entre os pesquisadores na área do turismo.

PALAVRAS-CHAVE: Sustentabilidade; Atividade Turística; Práticas de Gestão; Desenvolvimento Econômico.

\section{ABSTRACT}

Given the importance of tourism as an economic activity for Brazil and their effect on the environment to which it is inserted, to this end, questions to understand the discussions on the subject in the last ten years. This study aims at analyzing the main discussions related to sustainability in tourism in Brazil in the last decade. The specific objectives intended to: identify the main approaches within the theme of sustainability in tourism from Brazil and discuss how the variables contribute and / or affect the sustainability in tourism. Finally, it was concluded that the variables are interdependent, one complements the other, and all research as a whole contributes to the growth and improved quality of sustainability in tourism. However, the lack of research in this area is still large, even though the evidence on the sustainability issue, compared the number of articles published in journals, there is little that is debated among researchers in the area of tourism.

KEYWORDS: Sustainability; Tourism; Management Practices; Economic Development. 


\section{Introdução}

O turismo é uma atividade econômica em ascensão, especialmente no Brasil. De acordo com dados do Ministério do Turismo (2013), em 2012 foram cerca de 9.236.947 desembarques internacionais, 84.863.693 desembarques domésticos, gerando uma Receita Cambial (US\$ milhões) 6.645. Quando comparado ao ano de 2010, percebe-se que houve um crescimento de $59 \%$ nos desembarques internacionais, de $71,2 \%$ nos desembarques domésticos e 16,53\% na Receita Cambial.

O Ministério do Turismo faz uma projeção positiva para 2014, ano em que o Brasil sediará a Copa do Mundo. Estima-se que os empregos e ocupações criados nas atividades características do Turismo (ATC) crescerá de 372.172 em 2012, para 500.641 em 2014, um aumento de $34,52 \%$, é esperado um crescimento de $15,56 \%$ nos desembarques domésticos e de $21,03 \%$ nos desembarques internacionais.

Dados da Organização Mundial do Turismo (2013) - OMT, referentes ao primeiro semestre de 2011, indicam que a América do Sul liderou o crescimento do setor turístico. O crescimento da América do Sul foi de 15\%, em 2011, mais de três vezes superior à média mundial, de 4,4\%. No Brasil o crescimento foi de $11,57 \%$.

Ainda há uma projeção feita pela OMT, onde o turismo sul-americano deve mais que dobrar até 2030, continuando como terceiro maior receptivo de turistas, atrás de Europa e Ásia. O estudo indica que o volume deve mais que dobrar, passando de 24 para 56 milhões de chegadas de turistas.

Entretanto, Barretto (2011) afirma que para ocorrer o turismo é necessário a preparação de uma infraestrutura mínima para que os turistas frequentem o local, corroborando com Cruz (2001), que diz não existir uma relação do ser humano sem o meio, e ser impossível o homem viver no meio sem transformá-lo.

Para criar toda a infraestrutura que o turismo requer, o meio ambiente sofre grandes impactos e degradações. O meio ambiente é a matéria-prima da atividade turística, e talvez a solução para amenizar esses impactos seja a combinação entre turismo e sustentabilidade.

Em razão da importância do turismo como atividade econômica para o Brasil e o seu efeito no meio ao qual ele está inserido, para tal, questionase entender as discussões referentes ao tema nos últimos dez anos. Esse estudo tem como objetivo geral analisar as principais discussões referentes ao tema sustentabilidade na atividade turística do Brasil na última década. Como objetivos específicos pretende-se: identificar as principais abordagens dentro do tema sustentabilidade na atividade turística do Brasil e discutir de que modo as variáveis contribuem e/ou afetam a sustentabilidade na atividade turística.

A partir dos objetivos elencados, observa-se que o estudo será relevante para o setor turístico, pois visa identificar a interação com os âmbitos econômico, social e ambiental, por meio dos preceitos da sustentabilidade. Para a academia, será uma pesquisa relevante, pois observou-se a ainda incipiente existência de trabalhos realizados com o tema da pesquisa. 


\section{O Turismo}

Segundo Barretto (2011), a primeira definição sobre turismo foi dada pelo economista austríaco Hermann von Schullern zu Schattenhofen em 1991, em que escrevia "turismo é o conceito que compreende todos os processos, especialmente os econômicos, que se manifestam na chegada, na permanência, e na saída do turista de um determinado município, país ou estado".

De acordo com Arrillaga, (1976, p.25), "o turismo é o conjunto de deslocamentos voluntários e temporais determinados por causa alheias ao lucro; conjunto de bens, serviços e organizações que determinam e tornam possíveis estes deslocamentos e as relações e fatos que entre aqueles e os viajantes têm lugar".

De la Torre (1992, p.19), umas das definições mais recentes, define turismo como:

[...] um fenômeno social que consiste no deslocamento voluntário e temporário de indivíduos ou grupos de pessoas que, fundamentalmente por motivos de recreação, descanso, cultura ou saúde, saem do seu local de residência habitual para outro, no qual não exercem nenhuma atividade lucrativa nem remunerada, gerando múltiplas inter-relações de importância social, econômica e cultural.

A atividade turística "dirige o consumo aos lugares exóticos, transformando-os para serem comercializáveis, nos padrões de conforto e qualidade de vida do mundo moderno" (RODRIGUES, ARLETE, 2002, p.49).

Gastal (2002, p.9) traz a ideia de que:

O turismo é, talvez, o fenômeno mais globalizado, num mundo de globalizações. A pós-modernidade traz 0 apagamento das fronteiras e a busca de universalidades. Mas também traz o elogio da diferença. Nessa dialética, faz-se necessário que, da especificidade, nasça o que poderemos chamar de "turismo brasileiro", não apenas como o marketing de um destino emergente, mas como a construção de uma reflexão crítica que considere e construa o instrumental teórico com o qual iremos olhar e organizar os nossos entornos para melhor receber - à brasileira - os nossos visitantes, enquanto dialogamos como mundo. turismo:

Corroborando com Gastal (2002), Dias, (2003, p.14), afirma que o

[...] transformou-se numa das mais importantes faces da globalização, contribuindo para estreitar distâncias entre as diversas partes do globo e, ao mesmo tempo, para o aumento de uma consciência global. Diferentes povos, através da atividade turística, passam a compreender o lugar que ocupam no mundo e a ligação que possuem uns com os outros. 
O conceito de turismo é amplo e não existe singularidade, pois abrange diversas áreas. Dentre as definições apresentadas pode-se afirmar que todas tem em comum o deslocamento do turista, seja este por questão econômica, social, ou cultural.

\section{Sustentabilidade}

De acordo com a etimologia, sustentabilidade vem do latim sustentare, que significa suster, suportar, conservar em bom estado, manter, resistir. No dicionário de língua portuguesa, Michaelis (2012), sustentar significa "aguentar por baixo (o peso de); escorar, impedir de cair, servir de escora a, suportar, suster: Grandes colunas sustentavam a abóbada". Sustentável é tudo que é capaz de ser suportado, mantido.

Segundo Capra (2007, p. 312),

O conceito foi introduzido no início da década de 1980 por Lester Brown, fundador do Wordwatch Institute, que definiu comunidade sustentável como a que é capaz de satisfazer às próprias necessidades sem reduzir as oportunidades das gerações futuras.

Meníglia (2011, p. 39-40) afirma que:

Sustentabilidade é a habilidade, no sentido de capacidade, de sustentar ou suportar uma ou mais condições, atualmente configuradas na produção industrial concomitante à manutenção do meio ambiente equilibrado. Tal conceito cada vez mais se torna um princípio configurado no uso dos recursos naturais para a satisfação de necessidades presentes de forma equilibrada para não comprometer a satisfação das necessidades das gerações futuras, evitando-se o esgotamento dos recursos naturais.

Ainda, de acordo com Meníglia (2011, p. 40),

A ECO-92, Conferência sobre Meio Ambiente e Desenvolvimento, realizada em 1992, no Rio de Janeiro, consolidou o conceito sustentabilidade, colocando os termos meio ambiente e desenvolvimento juntos e concretizando a possibilidade apensas esboçada na Conferência de Estocolmo, em 1972, consagrando o uso do conceito de desenvolvimento sustentável, definido em 1987, pela Comissão Mundial sobre Meio Ambiente e Desenvolvimento (Comissão Brundtland).

Sasaki (2006, p.76) relata em seu livro que "a noção de sustentabilidade emerge como um paradigma do desenvolvimento, o qual, segundo Maurice Strong, Secretário da Conferência de Estocolmo em 1972, foi designado à época com o título de ecodesenvolvimento e amplamente divulgado pelos livros de lgnacy Sanchs". 
$\mathrm{Na}$ definição dada por Sanchs (1993, p.57) ecodesenvolvimento significa "desenvolvimento endógeno e dependente de suas próprias forças, tendo por objetivo responder à problemática da harmonização dos objetivos sociais e econômicos do desenvolvimento com uma gestão ecologicamente prudente dos recursos e do meio".

A despeito disso, Sasaki (2006, p. 78) afirma que há uma singela diferença entre ecodesenvolvimento e desenvolvimento sustentável:

o primeiro foca o atendimento das necessidades básicas da população, através da implantação de tecnologias apropriadas a cada ambiente, num processo que parte do mais simples paro o mais complexo. O segundo, por sua vez, apresenta a ênfase e a urgente necessidade de se estabelecerem políticas ambientais, e exalta a responsabilidade com gerações futuras, bem como com os problemas globais de natureza social, econômica, ambiental, cultural e espacial.

O governo brasileiro adota a definição exposto no documento Nosso Futuro Comum (1991), também conhecido como Relatório Brundtland (1987), publicado em 1987, no qual o uso sustentável dos recursos naturais deve "suprir as necessidades da geração presente sem afetar a habilidade das gerações futuras de suprir as suas".

Almeida (2010, p.2) afirma que "entre as recomendações do relatório constava a criação de uma declaração universal de proteção ambiental e desenvolvimento sustentável, que pudesse orientar as nações na transição para um desenvolvimento sustentável". Nesta perspectiva, o Relatório Brundtland "alertou para a importância do comprometimento das nações na busca de equilíbrio entre o crescimento econômico, as relações com meio ambiente e a sociedade nos empreendimentos humanos. A integração dessas três dimensões resultaria no Desenvolvimento Sustentável'.

Segundo Figueiredo (2005, p.12), o pilar do Ambiente "pretende salvaguardar a importância e fragilidade do mundo natural, enquanto suporte físico onde se desenrola a ação humana". De acordo com o autor, no segundo pilar, a Economia, são analisados os temas ligados à produção, distribuição e consumo de bens e serviços e deve-se levar em conta os outros dois aspectos.

Por último, o pilar da sociedade, trata-se do capital humano de um empreendimento, comunidade, sociedade como um todo. Nesse item, está contido também problemas gerais da sociedade como educação, violência e até o lazer. Sobre tal assunto, ainda são discutidos novos pilares, como a questão cultural, tecnológica, para complementar a sustentação da questão como um todo. 


\section{Procedimentos metodológicos}

Esta pesquisa tem caráter exploratório e descritivo, por sua perspectiva de ampliar as discussões relacionadas à sustentabilidade e 0 turismo e descritiva por objetivar apresentar as características do fenômeno. Sobre a pesquisa exploratória Gil (1999, p.43) a define como:

As pesquisas exploratórias têm como principal finalidade desenvolver, esclarecer e modificar conceitos e ideias, com vistas à formulação de problemas mais precisos ou hipóteses pesquisáveis para estudos posteriores. [...] Pesquisas exploratórias são desenvolvidas com o objetivo de proporcionar visão geral, de tipo aproximativo, acerca de determinado fato. Esse tipo de pesquisa é realizado especialmente quando o tema escolhido é pouco explorado e torna-se difícil sobre ele formular hipóteses precisas e operacionalizáveis.

Quanto às pesquisas descritivas, essas "expõe características de determinada população ou determinado fenômeno. Pode também estabelecer correlações entre variáveis e definir sua natureza. Não tem compromisso de explicar os fenômenos que descreve, embora sirva de base para tal explicação" (VERGARA, 2009, s/p). Gil (1999, p.44), destaca que as pesquisas descritivas "têm como objetivo primordial a descrição das características de determinada população ou fenômeno ou o estabelecimento de relações entre variáveis".

Em relação aos procedimentos adotados na coleta de dados, trata-se de pesquisa do tipo bibliográfica, por meio de análise de documentos secundários (revistas e anais de congressos). De acordo com Chizzotti (2001), são os documentos primários que contêm informações originais.

Foram analisados artigos científicos publicados em revistas nacionais, específicas em português, nas áreas de Administração, Ciências Contábeis e Turismo, avaliadas nos estratos "A1, A2, B1 e B2", pelo Qualis (um sistema de avaliação de periódicos dos programas de pós-graduação, da Coordenação de Aperfeiçoamento de Pessoal de Nível Superior CAPES, do Governo Federal), no período de 2003 a 2012.

Através da pesquisa foram encontradas 112 revistas, contendo mais de 50.000 artigos. Desses, apenas 486 tratam sobre o tema sustentabilidade, ou seja, menos de 1\%. Ainda, 52 tratam da questão sustentabilidade na atividade turística do Brasil, o que avigora a importância da implementação de novos trabalhos científicos nesse ramo.

Os dados foram analisados de forma qualitativa através da técnica de analise de conteúdo, sendo os mesmos organizados em etapas (VERGARA, 2009). Os 52 artigos foram separados por assuntos em comum, identificando, assim, cinco variáveis para serem discutidas, são elas: 1- planejamento, gestão para o desenvolvimento sustentável; 2formação e treinamento para sustentabilidade e 3-indicadores da sustentabilidade no turismo. 


\section{Apresentação das variáveis}

Na próxima seção serão apresentadas as variáveis identificadas para análise das publicações do período do recorte da pesquisa.

\section{Planejamento, gestão e a sustentabilidade}

A transição de turismo para o turismo sustentável é uma tarefa gradativa a ser empreendida. A intenção originária do conceito de sustentabilidade é ser expressão de crítica a um modelo de desenvolvimento supremo, socialmente iníquo e ambientalmente desperdiçador. A ideia de progresso da atividade turística engatada à noção de crescimento econômico pode sugerir a compreensão do turismo como se fosse uma "indústria" em ascensão. Para se reverter esse entendimento, tenta-se atrelar o turismo às diversas dimensões da sustentabilidade, tais como: a social, a econômica, a histórico-cultural, a ambiental, a espacial e a político institucional (DELAMARO et al., 2007).

A sustentabilidade deve ser aceita por todos os envolvidos na atividade, com suas responsabilidades especificadas e definidas com a finalidade de aprimorar as condições de vida das pessoas e ambientes. Assim, para as empresas do setor é de suma importância práticas coerentes com a redução dos impactos negativos causados pela atividade, a continuidade dos projetos, a ética norteando as relações.

Ainda nesta mesma linha de considerações, para as comunidades locais, é importante a participação na definição da direção a ser seguida em conjunto com os demais atores, na decisão do quanto se quer resgatar e alterar em sua cultura e modos de vida. Para os turistas a responsabilidade é auto-atribuída sobre a sua presença, suas possibilidades de interação e trocas com ambiente natural e cultural visitado e com o coletivo que o espera na sua volta. Os demais profissionais devem pensar e contribuir com a redução dos impactos negativos e descobrir as potencialidades e alcances do turismo feito de forma sustentável (RABINOVICI, 2011).

Em relação aos efeitos socioeconômicos e ambientais das atividades turísticas, Araujo (2008) define dois tipos predominantes de discursos gerados pelo desenvolvimento do turismo no Brasil. De um lado estão os que defendem o uso do turismo como uma alternativa e estratégia de desenvolvimento. Estes acreditam que o turismo pode avivar a economia, gerando benefícios diretos e indiretos ligados à criação de novos postos de trabalho e ocupação, contribuindo assim para a redistribuição de renda. Entre os que defendem 0 uso do turismo como alternativa de desenvolvimento estão, principalmente, os políticos, agências de financiamento de projetos de desenvolvimento e representantes da iniciativa privada.

No extremo oposto encontra-se um significativo número de estudiosos, membros de ONGs e representantes das comunidades afetadas, que levantam questionamentos e críticas sobre o turismo, enfatizando os seus efeitos negativos nas destinações e comunidades receptoras (ARAUJO, 2008). 
A outra postura sustenta que as:

\begin{abstract}
"ONGs têm papel preponderante, seja em conjunto com o Estado e a iniciativa privada ou separadamente, visando à conservação da bio e sociodiversidade, com participação e envolvimento em várias estratégias. Entre elas, destacamse: envolvimento na proteção da natureza e da cultura de comunidades locais; controle da qualidade das atividades ecoturísticas; captação de recursos e financiamento; educação ambiental e sensibilização; intercâmbio de informações entre atores locais, regionais e globais; elaboração de diretrizes e de diagnósticos; capacitação e apoio à participação comunitária; na pesquisa e difusão de conceitos, métodos e técnicas [...]" (RABINOVICI, 2011).
\end{abstract}

Rabinovici (2011) acredita que a maior contribuição das ONGs talvez esteja nas reflexões, tendências e filosofias propostas e exercitadas por elas. Ainda nesta mesma linha de considerações, ressalta que elas podem inovar e arriscar-se, em direção a novos horizontes e propostas, o que é diferente de buscar agregar valor ou diferenciação de mercado.

Outro aspecto levantado por Rabinovici (2011) são os "efeitos colaterais" causados pelas ONGs, exemplo disso ocorre quando estas tomam a frente de todas as ações e problemas, se colocam como agentes catalisadores de ações de conservação ambiental e assim oferecem seus projetos, arrecadam recursos financeiros e humanos e buscam parcerias, pode trazer como consequência a desmobilização da comunidade que passa a depender da sua tutela.

Para que a atividade turística ocorra de forma sustentável, é importante que ocorra o planejamento e gestão dessa atividade. É necessário que se determine os objetivos, as estratégias e alternativas para alcançar esses objetivos, a avaliação desta estratégia, e desenvolva algum procedimento para monitorar seus resultados. O planejamento é o exercício sistemático da antecipação, prevê os acontecimentos dentro de um determinado cenário, antecipa eventuais problemas, por conseguinte desenvolve planos para resolvê-los. Planejar é apenas a primeira etapa de um processo global que envolve planejamento, decisão e ação (DELAMARO et al.2007).

Corroborando com Delamaro et al. (2007), Alves, Medeiros e Macarajá (2012), acreditam que o planejamento no turismo seja fator fundamental na elaboração de estratégias de desenvolvimento de um ambiente turístico, pois é através do planejamento que se traça "pontos a serem aprimorados e revitalizados, com a finalidade de satisfazer o turista sem modificar os pontos a serem aprimorados conceitos de realização de um turismo sustentável' (ALVES; MEDEIROS; MACARAJÁ, 2012, p.21).

Se realizada sem planejamento, a atividade turística tem grandes possibilidades de produzir mais impactos negativos do que positivos. É primordial planejar buscando a sustentabilidade em modelos de gestões de políticas públicas coordenadas e integradas, pois assim aumenta a 
capacidade socioeconômica, ambiental e cultural da atividade. "O planejamento da atividade turística envolve a escolha de um cenário futuro que atenda aos interesses da maioria da população de um município, estabelecendo limites e regras e impondo condições que contribuem para o seu sucesso" (BOMFIM; ARGÔLO, 2008, p.49).

Inúmeros governos passaram a adotar medidas de planejamento turístico por interesse no grande potencial de desenvolvimento econômico e regional da atividade turística. Porém, muitas vezes o resultado desse planejamento não necessariamente atende aos desejos da comunidade local.

Ocorre nesses casos uma das principais características, o "de cima para baixo", que trata a comunidade como objeto, tirando-lhes o controle sobre seus destinos. "Sob influência do ideário neoliberal, muitos governos passaram a adotar uma postura empresarial em relação ao turismo a fim de aumentar a contribuição financeira do setor à receita do Estado" (DELAMARO et al., 2007, p. 109).

Ao referir-se a tal assunto é interessante destacar o artigo em que Delamaro et al. (2007) analisam a capacidade de gestão dos Órgão Municipais de Turismo, o envolvimento de atores sociais, os tipos e a efetividade dos planejamentos elaborados nos últimos anos, nos municípios do Cone Leste Paulista e conclui que as condutas de planejamento supremos não são suficientes para a promoção de um turismo sustentável, a dimensão político-institucional da sustentabilidade referida ao setor turístico é bastante precária em toda a região.

Se as situações hoje predominantes no planejamento se sustentarem e se o trivial potencial de crescimento do setor se concretizar, a tendência é o crescimento da pobreza e da exclusão, ameaçando todas as dimensões da sustentabilidade. Ressalta-se, a possível, preocupação na ênfase da iniciativa privada, pois, sabe-se bem que o interesse do setor privado é o lucro, raramente está interessado em necessidades sociais e ambientais de longo prazo. Por fim, analisou-se que "o turismo pode ser um elemento complementar e amplificador dos impactos positivos de uma política global de desenvolvimento social que só pode ser orquestrada pelo poder público" (DELAMARO et al., 2007, p.116).

Araujo (2008, p.98) também retrata o tema, ao fazer análise de stakeholders para o planejamento turístico sustentável e conclui que essa análise "é um importante instrumento metodológico para que se possa incluir, no processo de desenvolvimento de uma empresa, lugar ou destinação turística, aqueles atores e agentes sociais mais afeitos ao que se quer desenvolver". E, por fim afirma, "a inclusão dos representantes dos interesses afetados no processo de planejamento pode ser um forte componente na construção do desenvolvimento sustentável com base no turismo".

Hanai e Espíndola (2012) detectaram em seus estudos a existente necessidade de se fomentar esforços para o planejamento das estratégias de desenvolvimento e gestão sustentável do turismo, comprometido com as políticas, programas e planos específicos setoriais de desenvolvimento sustentável na região do município de Bueno Brandão (MG). 
Em seus estudos, foi revelado "a existência de atrativos naturais e culturais na área, o interesse e a disposição da população local no turismo, a demanda turística, bem como a existência de iniciativas e empreendimentos turísticos emergentes". Os resultados da pesquisa possibilitaram o esclarecimento de um cenário positivo e promissor, em relação ao desenvolvimento turístico do município, através de definição de políticas, planos, programas e projetos específicos de turismo (HANAl e ESPÍNDOLA, 2012, p.225).

As pesquisas realizadas abordam a variável de diferentes formas. No entanto, podemos perceber a preocupação por parte de algumas regiões quanto ao planejamento do turismo. Apesar do interesse por parte das comunidades anfitriãs, Alban (2008) e Sperb e Teixeira (2006) constataram insuficiência de estrutura governamental, o setor turístico precisa de estruturas de governança bem mais complexas do que as existentes nos demais setores.

Delamaro et al. (2007) concluíram que não falta apenas estrutura governamental, mas os procedimentos de planejamento hegemônicos como um todo não são suficientes para a promoção de um turismo sustentável. Santos e Mussoi (2009), ao estudar a possibilidade/necessidade de implementação de projetos turísticos no município de Cubatão (SP), percebeu-se diversas oportunidades de negócios desperdiçadas por conta do interesse incipiente dos gestores municipais em relação do potencial turístico.

Por fim, percebemos que as regiões estudadas contam com atrativos naturais suficientes para atrair turistas para região, contam com comunidades interessadas, mas falta planejamento por parte do governo.

\section{Formação e treinamento para Sustentabilidade}

No contexto da discussão sobre a formação e treinamento, salientase a preocupação para as práticas de desenvolvimento sustentável na formação do profissional de turismo da atualidade e o programa de sensibilização sustentável ao turismo.

De acordo com Martins e Neiman (2009), nas análises dos dados sobre cursos de graduação em turismo, nas instituições públicas de ensino superior, foi detectado que mesmo existindo grupos de pesquisa sobre Turismo Sustentável, há uma carência de abordagem sobre a temática sustentabilidade, porém, destacou-se uma tendência, nos últimos anos, principalmente nos cursos recém-criados, de uma fomentação às questões que envolvam aspectos socioeconômicos e ambientais.

Segundo Martins e Neiman (2009, p.142) "existem poucas instituições com ênfase clara em ações que envolvam a melhoria, através de pesquisas e ações, do bem estar humano, com alternativas sustentáveis para um melhor aproveitamentos dos recursos naturais e culturais".

Martins e Neiman (2009) afirmam que o problema está nas instituições de ensino superior, que preparam profissionais mais imediatos, práticos, que proponham soluções pontuais, esquecendo a missão de 
atender uma demanda por profissionais com visão multidisciplinar, crítica, reflexiva, necessária para inovar e discutir conceitualmente o Ecoturismo, comprometendo a transformação do Brasil num polo diferenciado do resto do mundo.

A função das instituições formadoras de profissionais de turismo é dotar seus alunos de uma capacidade reflexiva, fazendo permanentes críticas às questões ambientais, desenvolvendo o lado criativo, sem esquecer as ações voltadas para o mercado.

Hanai e Espíndola (2011) destacam o esforço em sensibilização da sociedade para o turismo sustentável, que é importante para a construção de novos paradigmas do desenvolvimento turístico, em que se incorpora a participação das comunidades locais no processo de planejamento e organização do turismo, levando esclarecimento e consciência aos anfitriões.

Após aplicarem o programa na região sul do estado de Minas Gerais, afirmam Hanai e Espíndola (2011) que a sensibilização local sobre a sustentabilidade do turismo permitiu aumentar a capacidade de participação e de organização da população local, fortalecer a capacidade de argumentação e de posicionamento de forma crítica frente a outros interlocutores, além de potencializar a atuação de forma conjunta e integrada para o desenvolvimento local do turismo sustentável.

Assim, verifica-se que além de uma formação reflexiva dos profissionais do setor de turismo, é importante a implementação de projetos para que a comunidade local dos polos turísticos possa ter consciência quanto a importância da realização do turismo de forma sustentável. A solução para alguns dos problemas de degradação causados pela atividade turística pode estar na união de profissionais qualificados e comunidade local consciente e preparada.

Há poucas pesquisas sobre formação e treinamento em relação a sustentabilidade na atividade turística. Foram encontrados apenas dois artigos, entres os 52 da área, percebe-se uma defasagem quanto ao estudo do assunto, o que não deveria acontecer, já que uma boa formação e treinamento é a base para disseminar e implantar a atividade turística sustentável de forma correta e produtiva.

\section{Indicadores da sustentabilidade no turismo}

Apontado como um dos principais desafios da humanidade ao longo do século XXI, o desenvolvimento sustentável caracteriza-se cada vez mais como um fim a ser alcançado pelas várias atividades econômicas. Com o turismo, uma das principais atividades econômicas em nível mundial, não é diferente. Entretanto, "desenvolvimento sustentável" e "turismo sustentável" são apenas conceitos, e como em todo conceito, só há uma forma de constatar sua efetividade, através da avaliação (CORDEIRO; LEITE; PARTIDÁRIO, 2010).

Desta constatação, surge uma pergunta incontornável, o que avaliar? Percebendo que este questionamento não tem sido muito discutido, 
Cordeiro, Partidário e Leite (2009, p.525) realizaram uma pesquisa com o intuito de "sugerir e discutir uma proposta de conteúdo mínimo a ser observada no escopo de qualquer processo direcionado para a avaliação da sustentabilidade do turismo". Ao fim, sugere-se que para alcançar seus objetivos, um processo de avaliação da sustentabilidade no setor do turismo deve:

i) adotar uma visão sobre o desenvolvimento sustentável; ii) estabelecer um processo de comunicação efetiva com as partes interessadas; iii) ser capaz de fornecer informações relevantes ao processo de tomada de decisão; iv) contemplar a participação pública; v) ser capaz de se adaptar às novas circunstâncias.

Avaliar algo como a sustentabilidade do turismo não é tarefa fácil e para auxiliar neste processo, existem ferramentas específicas. Em seu artigo, Cordeiro, Leite e Partidário (2010) apresentam cinco destas ferramentas. São elas: o Destination Scorecard do National Geographic Traveler, a Pegada Ecológica do Turismo (Tourism Ecological Footprint); o Barômetro de Sustentabilidade do Turismo (Barometer of Tourism Sustainability); o Sistema de Indicadores de Turismo Sustentável da Organização Mundial de Turismo (UNWTO); e o Core Set Indicators (CSI) of Sustainable Tourism da Agência Europeia de Estatística (Eurostat).

Por conseguinte, analisam criticamente o potencial de cada uma delas em relação as três categorias ("visão de desenvolvimento sustentável"; "comunicação efetiva" e "capacidade de apoio a decisão"), dessa forma, concluem que, apesar de possuírem suas virtudes, nenhuma delas está inteiramente capacitada para avaliar a sustentabilidade dos destinos turísticos. Auferiram que as metodologias falham na sua interpretação de sustentabilidade, o que corrobora com a assertiva de Butler (1999 apud CORDEIRO; LEITE; PARTIDÁRIO, 2010, p.62) no sentido de que o turismo sustentável continua mais no plano da retórica no que no plano da prática.

A despeito disso, Costa, Sawyer e Nascimento (2009, p. 57 e 58) desenvolveram uma pesquisa onde verificou-se de que maneira os indicadores de sustentabilidade são abordados no monitoramento das iniciativas de arranjos produtivos locais (APLs) de turismo no Brasil, dado que tais arranjos têm sido apontado como estratégicos nas políticas de desenvolvimento sustentável em escalas local e regional.

A partir de dados secundários, foram averiguados dez iniciativas de APL de turismo geridas pelo Sebrae - Serviço de Apoio à Pequena e Média Empresa. "Os indicadores de monitoramento foram analisados segundo quatro categorias: esfera, dados, interface e escopo". Obtiveram como principal conclusão a insuficiência da resposta do monitoramento dos projetos para a problemática da sustentabilidade, "visto que se concentra na dimensão econômica e não contempla, na maioria expressiva dos projetos, outras dimensões, social, ambiental, político-institucional e cultural'.

Dessa forma, observa-se que o resultado da pesquisa de Cordeiro, Leite e Partidário (2010) ratificou os resultados obtidos na pesquisa de Costa, Sawyer e Nascimento (2009). 
Diferente de Cordeiro, Leite e Partidário (2010) e Costa, Sawyer e Nascimento (2009), após efetuarem estudos sobre indicadores de sustentabilidade, conceitos, tipologias e aplicação ao contexto do desenvolvimento turístico local, Hanai e Espíndola (2011) chegaram a conclusão que conciliação entre as duas concepções de indicadores, qualitativo e quantitativo, é apropriado, relevante, apetecível e próspero para instaurar um bom sistema de monitoramento.

Afirmam que "os indicadores de sustentabilidade aplicados ao contexto do desenvolvimento turístico constituem instrumentos para a gestão e o controle da atividade turística de um destino, sendo sua seleção e monitoramento periódico componente fundamental para o planejamento e o desenvolvimento local" (HANAI; ESPÍNDOLA, 2011, p.146).

A afirmação de Hanai e Espíndola (2011) não é divergente das de Cordeiro, Leite e Partidário (2010) e Costa, Sawyer e Nascimento (2009), pois todos eles concordam no aspecto dos indicadores de sustentabilidade quanto instrumentos para a gestão e o controle da atividade turística, porém os dois últimos constataram que estes indicadores não estão completamente capacitados.

Ainda nesta mesma linha de considerações, Falcão e Gómez (2012, p.304), fizeram uma análise da sustentabilidade de destinos turísticos e desenvolveram uma proposta teórica de adequação do modelo de ciclo de vida de áreas turísticas às dimensões da sustentabilidade. Foi analisado o TALC (Tourism Areas Life Cycles), "um exemplo de estudos que se preocupou em criar parâmetros para avaliar a durabilidade da atividade turística de uma área em função do número de visitantes" e propuseram o ajuste do TALC às dimensões da sustentabilidade para que se alcance um resultado integrado entre os estágios do ciclo de vida e o retrato da sustentabilidade, quando aplicados a áreas turísticas.

Por fim, concluíram que "a adequação do TALC às dimensões da sustentabilidade se apresentou como uma proposta viável para aplicação em destinos turísticos, embora a escassez da literatura que trate as dimensões da sustentabilidade tenha sido o principal empecilho para encontrar o respaldo teórico de alguns indicadores e critérios de análise", contribuindo assim, "para que a experiência das pesquisadoras face a estudos turísticos se sobressaísse aos fundamentos teóricos consultados" (FALCÃO; GÓMEZ, 2012, p.319).

Buscando solução para o problema de implementação da conservação na Área de Proteção Ambiental (APA) Litoral Sul de Sergipe, região com "deficiente gestão aliada à falta de sensibilização ambiental dos visitantes e da comunidade local", Oliveira et al. (2008) desenvolveram uma pesquisa que objetivou selecionar indicadores de sustentabilidade para subsidiar a gestão do turismo nessa unidade de planejamento. Para o desenvolvimento do estudo, foi construído uma "matriz de indicadores Pressão-Estado-Impacto-Resposta (PEIR) [...] a metodologia usada foi proposta pela Organization to Cooperation and Economic Development (OCDE)" (OLIVEIRA et al., 2008, p. 46).

Segundo Oliveira et al. (2008, p.46), a perspectiva sistêmica foi de suma importância para a elaboração desta ferramenta de monitoramento, 
uma vez que irá auxiliar no planejamento e gestão do turismo, refletindo as necessidades das comunidades locais e toda a complexa interação entre os componentes da APA. Em síntese, "concluiu-se que a matriz de indicadores é um instrumento que pode auxiliar na reelaboração do Plano de Manejo da Área de Proteção Ambiental Litoral Sul, que atualmente se encontra sem mecanismos de gestão eficientes".

Falcão e Gómez (2012) e Oliveira et al. (2008), após aplicarem os indicadores de sustentabilidade, convergem quanto a sua viabilidade e eficiência.

Verifica-se que os indicadores da sustentabilidade são estudados com uma razoável frequência, dos 52 artigos sobre sustentabilidade na atividade turística do Brasil, ao menos $17 \%$ tratam de alguma forma sobre a variável. Espera-se que ocorra um aumento nessa área de pesquisa, pois tal variável é um instrumento de avaliação da viabilidade da sustentabilidade aplicada a atividade turística.

\section{Considerações finais}

A sustentabilidade na atividade turística do Brasil semeia-se como uma proposta de desenvolvimento econômico e de redução dos impactos negativos que o turismo causa ao meio ambiente e nas comunidades locais em que ocorre. Vem se constituindo numa alternativa viável, mesmo alguns autores tratando-a como uma utopia devaneia e inatingível.

Neste estudo questionou-se entender as discussões referentes ao tema nos últimos dez anos. Ao identificar as principais abordagens dentro do tema sustentabilidade na atividade turística do Brasil, foram encontradas 112 revistas, contendo mais de 50.000 artigos. Desses, apenas 486 tratam sobre o tema sustentabilidade, ou seja, menos de $1 \%$. Ainda, 52 tratam da questão sustentabilidade na atividade turística do Brasil, o que avigora a importância da implementação de novos trabalhos científicos nesse ramo.

A partir dos 52 artigos foram identificadas três variáveis: planejamento e gestão para o desenvolvimento sustentável, formação e treinamento, e indicadores da sustentabilidade.

Sobre as discussões teóricas, verifica-se a importância de que se ocorra de forma frequente para que haja atualização do assunto e se tenha um panorama do que está ocorrendo. Assim como outros temas, a sustentabilidade na atividade turística evolui, moderniza-se e deve acompanhar a globalização, se não ocorrer constantes discussões, periga estagnar e não acompanhar o progresso.

Visto que o segmento turístico é um potencial para o desenvolvimento econômico e social de muitas regiões, esta variável tornase a mestra. Pesquisas na área ajudam a desenvolver o setor, acarretando um grande volume de empregos, desenvolvimento social para as comunidades e até ativo quanto à preservação da cultura de determinadas regiões. Porém, é difícil afirmar que o segmento turístico contribui para a sustentabilidade, pois a partir do momento em que se altera a natureza, já está gerando algum tipo de impacto negativo, mas se desenvolvido com cautela, os impactos positivos vão sobressair aos negativos. 
A variável planejamento, gestão e o desenvolvimento sustentável está diretamente ligada ao desenvolvimento do setor turístico. É importante que se ocorra o planejamento e uma gestão competente para que o turismo se desenvolva e agregue valor a economia. Quanto a sustentabilidade, é primordial que ocorra planejamento, pois só assim poderá existir, uma vez que o Relatório Brundtland, publicado em 1987, define que o uso sustentável dos recursos naturais deve "suprir as necessidades da geração presente sem afetar a habilidade das gerações futuras de suprir as suas", ligando sustentabilidade diretamente ao planejamento, planejar para não faltar.

É imprescindível a formação e treinamento de qualidade para a sustentabilidade na atividade turística. Profissionais dotados de uma capacidade reflexiva, visão multidisciplinar, fazendo permanentes críticas às questões ambientais, desenvolvendo o lado criativo, sem esquecer das ações voltadas para o mercado, são necessários para inovar e discutir conceitualmente turismo sustentável, comprometendo a transformação do Brasil num polo diferenciado do resto do mundo. Além de estarem preparados para lidar com a atividade turística, colaborando para sua qualidade, inovação e desenvolvimento.

Os indicadores da sustentabilidade são formas de medição e avaliação, tanto de aplicabilidade, quanto de desempenho. É essencial avaliar se a sustentabilidade está sendo implementada, executada de forma correta, e se seus objetivos estão sendo atingidos, ou não, para que assim tomem as devidas providencias para aprimorá-la. Quanto ao turismo, é uma ferramenta que indica desenvolvimento econômico e social, através das avaliações feitas, podendo assim promover a cobrança de políticas que visam o incentivo ao turismo.

Por fim, conclui-se que as variáveis são interdependentes, uma complementa a outra, e a pesquisa de todas como um conjunto colabora para o crescimento e melhor qualidade da sustentabilidade na atividade turística. Porém, a falta de pesquisas na área ainda é grande, mesmo estando em evidência o tema sustentabilidade, quando comparado a quantidade de artigos publicados em periódicos, verifica-se que é pouco debatido entre os pesquisadores na área do turismo.

\section{Referências bibliográficas}

ALMEIDA, L.N. Sustentabilidade ambiental como estratégia empresarial na rede Walmart. VII SEGeT - Simpósio de Excelência em Gestão e Tecnologia 2010.

Disponível

em:<http://www.aedb.br/seget/artigos 10/235 Sustentabilidade\%20Ambiental\%2 0e\%20Estrategia\%20Empresarial\%20na\%20Rede\%20Walmart.pdf>. Acesso em: 01 de mar. de 2013.

ALVES, A. M.; MEDEIROS, J. L.; MARACAJÁ, K. F. B. Planejamento turístico: um estudo sobre o Plano de Desenvolvimento Integrado do Turismo Sustentável do Pólo Seridó. Caderno Virtual de Turismo, Rio de Janeiro, v. 12, n. 1, p. 17 - 29, 2012.

ARAUJO, L. M. Análise de Stakeholders para o Turismo Sustentável. Caderno Virtual de Turismo, Rio de Janeiro, v. 8, n. 1, p. 91 - 99, 2008. 
ARAÚJO, S. M. S.; SILVA, E. L. Ecoturismo, desenvolvimento sustentável e planejamento: política brasileira e potencialidades do sertão paraibano. Caderno Virtual de Turismo, Rio de Janeiro, v. 6, n. 3, p. 64 - 72, 2006.

BARRETTO, M. Manual de iniciação ao estudo do turismo. $20^{\mathrm{a}}$ ed. Campinas, SP: Papirus, 2011.

BOMFIM, N. R.; ARGOLO, D. S. Relação entre atividade turística, apropriação do território e patrimônio: uma contribuição para o planejamento sustentável do turismo na Bahia. RBTur, Caxias do Sul - RS, v. 2, n. 3, p. 41 - 53, 2008.

CAPRA, F. e col. Alfabetização Ecológica: A educação das crianças para um mundo sustentável. São Paulo: Cultrix, 2007, p. 312.

CHIZZOTTI, A. Pesquisa em ciências humanas e sociais. 5.ed. São Paulo: Cortez, 2001.

CORDEIRO, I.; BENTO, E.; BRITTO, C. Turismo e desenvolvimento sustentável: considerações sobre o modelo de resorts no litoral nordeste do Brasil. Caderno Virtual de Turismo, Rio de Janeiro, v. 11, n. 3, p. 355 - 369, 2011.

CORDEIRO, I.; LEITE, N. K.; PARTIDÁRIO, M. R. Instrumentos de avaliação de sustentabilidade de destinos turísticos: uma revisão de literatura. Caderno Virtual de Turismo, Rio de Janeiro, v. 10, n. 2, p. 49 - 64, 2010.

CORDEIRO, I. D.; PARTIDÁRIO, M. R.; LEITE, N. K. Considerações Sobre o Escopo de um Processo de Avaliação da Sustentabilidade do Turismo. Revista Turismo em Análise, São Paulo, v. 20, n. 3, p. 525 - 540, 2009.

COSTA, H. A.; SAWYER, D. R.; NASCIMENTO, E. P. Monitoramento de APL de turismo no Brasil: o (não) lugar das dimensões da sustentabilidade. RBTur, Caxias do Sul - RS, v. 3, n. 3, p. 59 - 79, 2009.

CRUZ, R. C. A. Introdução a geografia do turismo. São Paulo: Roca, 2001.

DE LA TORRE, O. El turismo, fenómeno social. México: Fondo de Cultura Económica, 1992.

DELAMARO, M.C.; TOMASELLA JUNIOR, S.; BRITO, R.M.; GASPAR, T.A. A dinâmica das políticas públicas do setor de turismo nos municípios do Cone Leste Paulista: reflexões sobre a dimensão político-institucional da sustentabilidade. Caderno Virtual de Turismo, Rio de Janeiro, v. 7, n. 1, p. 104 - 116, 2007.

DIAS, R. Planejamento do turismo: política e desenvolvimento do Turismo no Brasil. São Paulo: Atlas, 2003.

DIAS, R. Turismo sustentável e meio ambiente. São Paulo: Atlas, 2003b.

FIGUEIREDO, A. M. L. A função turística do patrimônio: questionamentos sobre a ideia de sustentabilidade do turismo cultural. Caderno Virtual de Turismo, Rio de Janeiro, v. 5, n. 4, p. 43 - 49, 2005.

FIGUEIREDO, O.J.M.G. Ciência e Sustentabilidade: dois estudos de caso de professoras de ciências físicas e naturais do $3^{\circ}$ ciclo do ensino básico. Lisboa, 2005. Disponível em: <http://pt.scribd.com/doc/65898834/9/Os-tres-pilares-dodesenvolvimento-sustentavel> 
GASTAL, S.(org.). Turismo: Investigação e Crítica. São Paulo: Contexto, 2002. - Coleção turismo Contexto.

GIL, A.C. Métodos e técnicas de pesquisa social. $5^{\underline{a}}$ ed. São Paulo: Atlas. 1995.

HANAI, F.Y. Desenvolvimento sustentável e sustentabilidade do turismo: conceitos, reflexões e perspectivas. Revista Brasileira de Gestão e Desenvolvimento Regional, Taubaté - SP, v. 8, n. 1, p. 198-231, jan-abr/2012.

HANAI. F.Y.; ESPÍNDOLA, E.L.G. Programa de Sensibilização Sustentável do Turismo: Uma Proposta Para Envolvimento e Participação de Comunidades Locais. Revista Turismo em Análise, São Paulo, v. 22, n. 1, p. 4 24, 2011.

HANAI. F.Y.; ESPÍNDOLA, E.L.G. Indicadores de sustentabilidade: conceitos, tipologias e aplicação ao contexto do desenvolvimento turístico local. RGSA, São Paulo, v. 5, n. 3, p. 135 - 149, 2011.

HANAI. F.Y.; ESPÍNDOLA, E.L.G. O planejamento e a gestão do turismo sustentável na região de Bueno Brandão (MG/ Brasil). Caderno Virtual de Turismo Rio de Janeiro, v. 12, n. 2, p. 224 - 238, 2012.

MANÍGLIA, E.(org.). Direito, Políticas Públicas e Sustentabilidade: Temas atuais. São Paulo: Cultura Acadêmica: Editora UNESP, 2011.

MICHAELIS. Dicionário Escolar Língua Portuguesa: Col. Cidadania ao Pé da Letra. Melhoramentos, 2012

Ministério do Turismo, Dados e fatos. Disponível em:

$<$ http://www.dadosefatos.turismo.gov.br/dadosefatos/home.html> Acesso em: 22 de fev. de 2013.

Ministério do Turismo, Dados e fatos. Disponível em:

$<$ http://www.dadosefatos.turismo.gov.br/dadosefatos/geral interna/noticias/deta lhe/20111013-3.html> Acesso em: 02 de mar. de 2013.

Ministério do Turismo, Dados e fatos. Disponível em:

$<$ http://www.dadosefatos.turismo.gov.br/dadosefatos/geral interna/noticias/deta lhe/20110909.html> Acesso em: 02 de mar. de 2013.

NEIMAN, Z.; MARTINS, M. R. A questão da qualidade na formação dos profissionais para o turismo sustentável. Caderno Virtual de Turismo, Rio de Janeiro, v. 9, n. 1, p. 128 - 147, 2009.

OLIVEIRA, I.S.S.; OLIVEIRA, D.C.; GOMES, L.J.; FERREIRA, R.A. Indicadores de sustentabilidade: diretrizes para a gestão do turismo na APA litoral sul de Sergipe. Caderno Virtual de Turismo, Rio de Janeiro, v. 8, n. 2, p. 46 - 55, 2008.

OLIVEIRA FILHO, R.O.; MONTEIRO, M.L. Ecoturismo no Parque Nacional Serra da Capivara: trata-se de uma prática sustentável? Revista Turismo em Análise, São Paulo, v. 20, n. 2, p. 230 - 250, 2009.

RABINOVICI, A. Ambientalismo, Organizações Não Governamentais e a busca pela sustentabilidade no Turismo. Revista Turismo em Análise, São Paulo, v. 22, n. 1, p. 44 - 70, 2011. 
SANCHS, I. Estratégias de transição para o século XXI: desenvolvimento e meio ambiente. São Paulo: Nobel, 1993.

SANTOS. A.F.L. O desenvolvimento sustentável do turismo em Cubatão (SP). Caderno Virtual de Turismo, Rio de Janeiro, v. 9, n. 1, p. 29 - 37, 2009.

SANTOS, S.M. Bases sócio-ambientais para implantação do ecoturismo na reserva de desenvolvimento sustentável do Piranha. Caderno Virtual de Turismo, Rio de Janeiro, v. 9, n. 1, 88 - 104, 2009.

VERGARA, S.C. Projetos e relatórios de pesquisa em administração. São Paulo: Editora Atlas, 11를. Ed., 2009.

Nathália Roncada de Freitas: Universidade Federal de Mato Grosso, Cuiabá, MT, Brasil.

E-mail: nathaliaroncada@hotmail.com

Link para o currículo Lattes: http://lattes.cnpq.br/8947400635460015

Paulo Augusto Ramalho de Souza: Universidade Federal de Mato Grosso, Cuiabá, MT, Brasil.

E-mail: pauloramalho@cpd.ufmt.br

Link para o currículo Lattes: http://lattes.cnpq.br/2037264549693033

Elisandra Marisa Zambra: Universidade Federal de Mato Grosso, Cuiabá, MT, Brasil.

E-mail: elisandrazambra@gmail.com

Link para o currículo Lattes: http://lattes.cnpq.br/6642810118092079

Maria do Carmo Romeiro: Universidade Municipal de São Caetano do Sul, São Caetano do Sul, SP, Brasil.

E-mail:mromeiro@uscs.edu.br

Link para o currículo Lattes: http://lattes.cnpq.br/8770370258926383

Raquel da Silva Pereira: Universidade Municipal de São Caetano do Sul, São Caetano do Sul, SP, Brasil.

E-mail: raquelspereira@uscs.edu.br

Link para o currículo Lattes: http://lattes.cnpq.br/8196522386086079

Data de submissão: 18 de novembro de 2013

Data de recebimento de correções: 18 de novembro de 2013

Data do aceite: 25 de março de 2014

Avaliado anonimamente 